\title{
Model Pembelajaran Numbered Heads Together (NHT) sebagai Upaya untuk Meningkatkan Prestasi Belajar Matematika Siswa Kelas V SD
}

\section{Ni Luh Widiani ${ }^{*}$}

${ }^{1}$ SD Negeri 1 Suwug Singaraja, Indonesia

\section{ART ICLE IN F O}

Article history:

Received July 16, 2021

Revised July 20, 2021

Accepted October 20, 2021

Available online November 25, 2021

Kata Kunci:

Numbered Heads Together, Prestasi Belajar

Keywords:

Numbered Heads Together, Learning Achievement

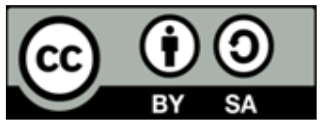

This is an open access article under the CC BY-SA license.

Copyright (ㅇ 2021 by Author. Published by Universitas Pendidikan Ganesha.

\begin{abstract}
A B S T R A K
Rendahnya prestasi belajar siswa disebabkan oleh proses pembelajaran yang belum maksimal. Penelitian ini bertujuan untuk menganalisis model pembelajaran Numbered Heads Together (NHT) sebagai upaya untuk meningkatkan prestasi belajar matematika siswa kelas V SD. Jenis penelitian merupakan penelitian tindakan kelas. Metode pengumpulan data menggunakan metode tes. Analisis data yang diperoleh menggunakan metode analisis deskriptif. Data yang dihasilkan dari penelitian ini terdiri dari data awal, data siklus I ,dan data siklus II. Dari data awal diperoleh rata-rata kelas baru mencapai 47,5 dan ketuntasan belajarnya baru mencapai $27 \%$. Data ini jauh di bawah harapan mengingat KKM mata pelajaran Matematika di sekolah ini adalah 67. Pada siklus I sudah terjadi peningkatan yaitu rata-rata kelasnya mencapai 67,8 dan persentase ketuntasan belajar baru mencapai $59 \%$. Pada siklus II perolehan rata-rata kelas sudah mencapai 72,2 dan persentase ketuntasan belajar sudah $86 \%$. Data pada siklus II ini sudah sesuai dengan harapan sebagai akibat diterapkannya model pembelajaran yang bersifat konstruktivis. Jadi, model pembelajaran Numbered Heads Together (NTH) dapat meningkatkan prestasi belajar siswa. Implikasi penelitian ini diharapkan dapat membantu meningkatkan prestasi belajar siswa dengan menerapkan model pembelajaran kooperatif tipe Numbered Heads Together (NHT).
\end{abstract}

\section{A BSTRACT}

The low learning achievement of students is caused by the learning process that has not been maximized. This study aims to analyze the Numbered Heads Together (NHT) learning model to improve the mathematics learning achievement of fifth-grade elementary school students. This type of research is classroom action research. Methods of data collection using the test method. Analysis of the data obtained using the descriptive analysis method. The data generated from this study consisted of initial data, cycle I data, and cycle II data. From the initial data, the average class reached 47.5, and the learning completeness only reached $27 \%$. This data is far below expectations, considering the KKM for Mathematics in this school is 67. In the first cycle, there has been an increase. Namely, the average class reaches 67.8 , and the percentage of learning completeness only reaches $59 \%$. In the second cycle, the average class achievement has reached 72.2, and the percentage of learning completeness is $86 \%$. The data in the second cycle is in line with expectations due to the constructivist learning model. So, the Numbered Heads Together (NTH) learning model can improve student achievement. The implications of this research are expected to help improve student achievement by applying the Numbered Heads Together (NHT) cooperative learning model.

\section{PENDAHULUAN}

Pendidikan memiliki peranan yang sangat penting dalam meningkatkan sumber daya manusia. Melalui pendidikan seseorang akan mampu untuk meningkatkan berbagai kemampuan dan keterampilannya (Andesta, 2021; Anjarsari, 2018; Persada et al., 2020). Pendidikan juga dapat menciptakan generasi yang unggul dan kompetitif dalam upaya untuk menghadapi tantangan yang akan terjadi di masa depan (Andrian \& Rusman, 2019; Husain \& Kaharu, 2021). Untuk tercapainya pendidikan 
yang lebih baik, diperlukan sebuah komitmen dalam membangun kemandirian yang dapat menopang kemajuan pendidikan di masa depan. Salah satu yang berperan penting dalam keberhasilan peserta didik adalah prestasi belajar siswa (Laksono et al., 2016; Syafari \& Montessori, 2021). Peningkatan prestasi belajar peserta didik sangat bergantung pada pemilihan strategi yang tepat dan efektif dalam upaya mengembangkan kreativitas, kemampuan, dan sikap inovatif peserta didik(Laksono et al., 2016; Mahfudi, 2020). Untuk itu, perlu dibina dan dikembangkan pengelolaan program pengajaran dengan metode dan strategi pembelajaran yang kaya dengan variasi metode atau variasi model. Guru harus menguasai keterampilan mengajar dengan baik. Namun kenyataannya, kondisi yang diharapkan tersebut tidak didukung dengan pengetahuan dan pemahaman guru mengenai strategi, metode, teknik, pendekatanpendekatan tertentu, sehingga prestasi belajar anak akan menjadi rendah (Prayito, 2011; Rufaidah, 2019). Proses belajar mengajar juga belum maksimal. Selain itu, rendahnya hasil belajar matematika siswa yang menyebabkan penurunan prestasi belajar siswa (Bungsu et al., 2018; Handayani \& Septhiani, 2021). Hal ini juga terjadi pada siswa kelas V semester 1 tahun ajaran 2017 - 2018 di SD Negeri 1 Suwug ternyata baru mencapai rata-rata 47 dengan persentase ketuntasan belajar 27\%. Hal ini terjdi karena beberapa sebab sebagi berikut. (1) Kurangnya kemauan guru mengembangkan model pembelajaran; (2) Kurangan kemampuan guru memahami inti pembelajaran; (3) Kurangnya kemampuan guru nmenerapkan teoriteori pembelajaran terbaru; (4) Kurangnya kemampuan guru memahami karakteristik peserta didik; (5) Kurangnya keberanian siswa untuk menyampaikan pertanyaan terhadap permasalahan yang dihadapi.

Terdapat berbagai macam upaya yang dapat dilakukan untuk meningkatkan prestasi belajar siswa, salah satunya yakni menggunakan model pembelajaran yang aktif dan inovatif. Salah satu model pembelajaran yang dapat digunakan yakni model pembelajaran Numbered Heads Together (NHT). Number Heads Together adalah suatu model pembelajaran yang lebih mengedepankan kepada aktivitas siswa untuk mencari, mengolah, dan melaporkan informasi dari berbagai sumber yang akhirnya dipresentasikan di depan kelas (Diah Purwati et al., 2019; Kurnia \& Damayani, 2019; Yenni, 2016). Pada dasarnya, model NHT merupakan suatu bentuk varian diskusi kelompok. Model pembelajaran ini biasanya diawali dengan mengelompokkan siswa menjadi beberapa kelompok. Setiap dalam kelompok sengaja diberi nomor untuk memudahkan kerja kelompok, mengubah posisi kelompok, menyusun materi, mempresentasikan, dan mendapat tanggapan dari kelompok lain (Maman \& Rajab, 2016; SY et al., 2016). Model ini melibatkan semua siswa baik secara fisik, emosional maupun intelektual (Diah Purwati et al., 2019; Iskandar \& Leonard, 2019; Juliartini \& Arini, 2017). Melalui pemilihan model NHT, diharapkan pembelajaran dapat lebih bermakna dan memberi kesan yang kuat kepada siswa dalam belajar kompetensi kejuruan. Model pembelajaran kooperatif tipe NHT diharapkan mampu mengatasi kelemahan pembelajaran model ceramah. Sehingga dapat tercipta suasana pembelajaran yang interaktif. Beberapa temuan sebelumnya menyatakan model pembelajaran kooperatif tipe NHT memiliki pengaruh besar terhadap hasil belajar dan motivasi belajar siswa (Arjuniwati, 2019; Astuti, 2019). Model pembelajaran NHT secara signifikan mampu meningkatkan hasil belajar siswa kelas III Sekolah dasar (Juliartini \& Arini, 2017; Lestari, 2018; Sinaga, Amran Jahot \& Harun Sitompul, 2017). Berdasarkan beberapa penelitian tersebut dapat dikatakan bahwa model pembelajaran NHT sangat cocok dibelajarkan kepada siswa, hal ini dikarenakan model pembelajaran ini mampu meningkatkan hasil belajar serta motivasi belajar siswa. Hanya saja pada penelitian sebelumnya belum terdapat kajian yang membahas secara bersama-sama mengenai peningkatan prestasi belajar siswa menggunakan model number head together (NHT). Dengan demikian, tujuan penelitian ini untuk menganalisis model pembelajaran Numbered Heads Together (NHT) sebagai upaya untuk meningkatkan prestasi belajar matematika siswa kelas V SD.

\section{METODE}

Penelitian ini adalah penelitian tindakan kelas yang dilaksanakan di kelas V SD Negeri 1 Suwug dengan jumlah siswa sebanyak 22 orang, terdiri dari 7 orang perempuan dan 15 orang laki-laki. Penelitian ini dilaksanakan pada semester I tahun pelajaran 2019/2020 selama 4 bulan dari bulan Juli sampai dengan Oktober 2017. Rancangan untuk mendapatkan keberhasilan penelitian. Penelitian tindakan kelas ini dilaksanakan sesuai dengan rancangan penelitian seperti pada gambar di atas. Penelitian ini dimulai dari siklus I dimulai dengan perencanaan seperti: (1) menyususn RPP, (2) menentukan materi yang akan dijadikan materi penelitian, (3) mengembangkan format evaluasi, (4) menyusun Lembar Kerja Siswa yang akan diselesaikan oleh tiap kelompok, (5) menyusun tes prestasi belajar siswa. Pada tahap pelaksanaan, peneliti melaksanakan semua perencanaan pembelajaran yang telah disusun. Secara garis besar pelaksanaan proses pembelajaran adalah: menyampaikan tujuan dan motivasi siswa, menyajikan Informasi, penomoran, mengajukan pertanyaan/permasalahan, berpikir bersama, menjawab (Evaluasi), memberikan penghargaan. Mengacu pada hasil penilaian tes prestasi belajar, guru mengadakan pengamatan. Refleksi adalah sarana untuk melakukan pengkajian kembali terhadap tindakan yang telah 
dilakukan. Kegiatan refleksi berguna untuk melakukan peninjauan, membuat gambaran kerja yang hidup dalam situasi proses penelitian, hambatan yang muncul dalam tindakan dan kemungkinan lain muncul selama proses penelitian. Adapun teknik pengumpulan data yang digunakan pada penelitian ini adalah metode tes prestasi belajar. Metode analisis data menggunakan metode deskriptif. Data kuantitatif dianalisis dengan mencari mean, median, modus, membuat interval kelas, dan melakukan penyajian dalam bentuk Tabel.

\section{HASIL DAN PEMBAHASAN}

Hasil

Berdasarkan hasil penelitian ini dari siklus I dan siklus II, rekapitulasi hasil pembelajaran disajikan pada Tabel 1. Pada siklus I, rata-rata hasil belajar 67,8 dengan ketuntasan belajar sebesar 59\%. Hasil belajar tersebut masih belum mencapai indikator keberhasilan yang ditetapkan dalam penelitian ini. Masih rendahnya hasil belajar tersebut disebabkan oleh: (1) kemampuan secara maksimal mengarahkan siswa agar giat belajar agak sulit diupayakan akibat kebiasaan peserta didik yang lebih senang santai, (2) dengan strategi yang berbeda siswa masih menunggu perintah guru, (3) pendekatan pembelajaran belum mampu membuat siswa untuk rajin belajar, (4) pembelajaran adalah sebuah sistem, sehingga banyak hal yang harus terkait. Keterkaitan ini belum maksimal mampu diupayakan. Pada siklus II, rata-rata hasil belajar siswa sebesar 72,2 dengan ketuntasan belajar sebesar 86\%. Hasil belajar ini telah melampaui indikator keberhasilan yang ditetapkan dalam penelitian ini. Pada siklus II ini semua kekurangan yang ada pada siklus I diperhatikan dengan baik dan dilakukan inovasi-inovasi yang lebih maksimal agar hasil yang diperoleh hasil sesuai tujuan penelitian ini. Siswa yang belum aktif diupayakan dengan pemberian rangsangan-rangsangan, motivasi-motivasi, arahan-arahan agar mereka ikut terlibat aktif dalam pembelajaran. Siswa yang lain juga diarahkan oleh guru lebih gencar memberi pertanyaan-pertanyaan yang menuntun keaktifaan belajar. Langkah-langkah model pembelajaran NHT, siswa harus diupayakan agar mampu menemukan sendiri apa isi dari materi lewat pemberian pertanyaan-pertanyaan, atau masalah-masalah yang menuntun ke pembelajaran yang lebih maksimal. Dari semua tindakan yang sudah dilakukan pada siklus II ini ternyata hasil yang diperoleh sudah melebihi tuntutan indikator keberhasilan penelitian yang semula di targetkan $80 \%$ hasilnya meningkat menjadi $86 \%$ dengan rata-rata kelas mencapai 72,2. Hasil ini jauh diatas nilai KKM yang dicanangkan yaitu 67. Keberhasilan ini tentu diperolah akibat kerja keras yang dilakukan. Dengan hasil tersebut penelitian sudah dianggap berhasil dan tidak diteruskan ke siklus berikutnya.

Tabel 1. Perkembangan Hasil Belajar

\begin{tabular}{ccc}
\hline Uraian & Siklus I & Siklus II \\
\hline Jumlah Nilai & 1495 & 1590 \\
Rata-rata (Mean ) & 67,8 & 72,2 \\
Kriteria Ketuntasan Minimal & 67 & 67 \\
Jumlah siswa yang remidi & 9 & 3 \\
Jumlah siswa yang diberi pengayaan & 13 & 19 \\
Presentase ketuntasan belajar & $59 \%$ & $86 \%$ \\
\hline
\end{tabular}

\section{Pembahasan}

Pembelajaran dengan menggunakan metode pembelajaran kooperatif tipe Numbered Heads Together (NHT) dapat meningkatkan prestasi belajar siswa. Model Number Head Together (NHT) merupakan suatu model pembelajaran yang mengutamakan peran aktif siswa, serta mengajak siswa untuk belajar sambil bermain (Kurnia \& Damayani, 2019; Simanungkalit, 2021). Proses pembelajaran yang demikian tentu akan menarik perhatian siswa siswa sekolah dasar. Siswa sekolah dasar pada umumnya merupakan siswa yang memiliki karakteristik senang mencari tahu hal-hal baru sesuai dengan keinginannya. Oleh karena itu, guru mampu berperan sebagai fasilitator untuk memfasilitasi, menunjang, serta mengarahkan rasa ingin tahu siswa ke arah yang lebih positif. Proses pembelajaran yang disesuaikan dengan karakteristik siswa tentunya akan meningkatkan rasa nyaman siswa saat belajar, sehingga siswa mampu termotivasi dengan baik untuk meningkatkan prestasi belajar (Astuti, 2019; Susilo \& Khabibah, 2010). Selain itu, melalui model pembelajaran kooperatif tipe numbered heads together (NHT) siswa di beri kesempatan untuk mengalami sendiri atau melakukan sendiri, sehingga pembelajaran lebih bermakna.

Model pembelajaran kooperatif tipe numbered heads together (NHT) dapat meningkatkan prestasi belajar siswa. Prestasi belajar matematika sama dengan prestasi belajar bidang studi yang lain merupakan hasil dari proses belajar siswa. Prestasi belajar merupakan kemampuan-kemampuan yang dimiliki oleh 
siswa sebagai akibat perbuatan belajar atau setelah menerima pengalaman belajar, yang dapat dikatagorikan menjadi tiga ranah, yakni ranah kognitif, afektif, dan psikomotor (Rahmat, 2018; Suarni, 2017). Prestasi belajar mempunyai arti dan manfaat yang sangat penting bagi anak didik, pendidik, orang tua/wali murid dan sekolah, karena nilai atau angka yang diberikan merupakan manifestasi dari prestasi belajar siswa dan berguna dalam pengambilan keputusan atau kebijakan terhadap siswa yang bersangkutan maupun sekolah (Hamdu, 2011; Mahfudi, 2020). Prestasi belajar merupakan kemampuan siswa yang dapat diukur, berupa pengetahuan, sikap dan keterampilan yang dicapai siswa dalam kegiatan belajar mengajar. Oleh karena itu, dalam meningkatkan prestasi belajar diperlukan model pembelajaran seperti model pembelajaran kooperatif tipe numbered heads together (NHT). Model pembelajaran kooperatif tipe NHT memiliki pengaruh besar terhadap hasil belajar dan motivasi belajar siswa (Arjuniwati, 2019; Astuti, 2019). Model pembelajaran NHT secara signifikan mampu meningkatkan hasil belajar siswa kelas III Sekolah dasar (Juliartini \& Arini, 2017; Lestari, 2018; Sinaga, Amran Jahot \& Harun Sitompul, 2017). Berdasarkan analisis hasil penelitian yang didukung oleh beberapa penelitian terdahulu dapat dikatakan bahwa metode NHT sangat cocok digunakan untuk meningkatkan prestas belajar siswa sekolah dasar. Implikasi penelitian ini diharapkan dapat membantu meningkatkan prestasi belajar siswa dengan menerapkan model pembelajaran kooperatif tipe Numbered Heads Together (NHT).

\section{SIMPULAN}

Pembelajaran dengan menggunakan metode pembelajaran kooperatif tipe Numbered Heads Together (NHT) dapat meningkatkan prestasi belajar siswa. Guru harus mempunyai pengetahuan dan keterampilan dalam menyusun instrumen pembelajaran dan menerapkan pendekatan atau model pembelajaran di sekolah. Dengan referensi model dan pendekatan, guru dapat memvariasikan kegiatan belajar mengajar yang pada akhirnya dapat menarik minat belajar siswa terhadap pembelajaran matematika. Salah satu model yang diterapkan adalah pembelajaran kooperatif tipe Numbered Heads Together (NHT).

\section{DAFTAR RUJUKAN}

Andesta, D. (2021). Analisis Kebutuhan Anak Usia Sekolah Dasar dan Implikasinya dalam Penyelenggaraan Pendidikan. JIP: Jurnal Ilmiah PGMI, 4(1), 82-97. https://doi.org/10.19109/jip.v4i1.2269.

Andrian, Y., \& Rusman, R. (2019). Implementasi Pembelajaran Abad 21 dalam Kurikulum 2013. Jurnal Penelitian Ilmu Pendidikan, 12(1), 14-23. https://doi.org/10.21831/jpipfip.v12i1.20116.

Anjarsari, A. D. (2018). Penyelenggaraan Pendidikan Inklusi pada Jenjang SD, SMP, dan SMA Di Kabupaten Sidoarjo. JPI (Jurnal Pendidikan Inklusi), 1(2), 91. https://doi.org/10.26740/inklusi.v1n2.p91-104.

Arjuniwati. (2019). Motivasi dan Hasil Belajar Melalui Penerapan Model Pembelajaran Numbered Heads Together (NHT) pada Materi Peluang Mata Pelajaran Matematika Kelas XII. Jurnal Pendidikan Tambusai, 3(1), 1-13. https://doi.org/10.31004/jptam.v3i1.197.

Astuti, W. (2019). Pengaruh Model Numbered Heads Together (NHT) terhadap Motivasi Belajar dan Hasil Belajar IPS Siswa Kelas III Sekolah Dasar. Jurnal Basicedu, 3(2), 605-610. https://doi.org/10.31004/basicedu.v3i2.45.

Bungsu, T. K., Vilardi, M., Akbar, P., \& Bernard, M. (2018). Pengaruh Kemandirian Belajar terhadap Hasil Belajar Matematika di SMKN 1 Cihampelas. Journal On Education, 1(2), 382-389. https://doi.org/10.31004/joe.v1i2.78.

Diah Purwati, N. L. P., Wibawa, I. M. C., \& Margunayasa, I. G. (2019). Pengaruh Numbered Head Together Berbantuan Gambar terhadap Penguasaan Kompetensi Pengetahuan IPA. Jurnal Pedagogi Dan Pembelajaran, 2(3), 282. https://doi.org/10.23887/jp2.v2i3.19275.

Hamdu, G. \& L. A. (2011). Pengaruh Motivasi Belajar Siswa terhadap Prestasi Belajar IPA di Sekolah Dasar. Jurnal Penelitian Pendidikan, 12(1).

Handayani, D., \& Septhiani, S. (2021). Pengaruh Kecerdasan Emosional Aspek Kesadaran Diri terhadap Prestasi Belajar Matematika. Jurnal Cendekia: Jurnal Pendidikan Matematika, 05(02), 1352-1358. https://doi.org/10.31004/cendekia.v5i2.585.

Husain, R., \& Kaharu, A. (2021). Menghadapi Era Abad 21: Tantangan Guru Pendidikan Anak Usia Dini di Kabupaten Bone Bolango. Jurnal Obsesi: Jurnal Pendidikan Anak Usia Dini, 5(1), 85-92. https://doi.org/10.31004/obsesi.v5i1.527.

Iskandar, A. P., \& Leonard, L. (2019). Modifikasi Model Pembelajaran Tipe Numbered Heads Together (NHT) dengan Strategi Pembelajaran Tugas dan Paksa terhadap Kemampuan Penalaran Matematika Siswa. Jurnal Penelitian Matematika Dan Pendidikan Matematika, 4(1). 
https://doi.org/10.26486/jm.v4i1.801.

Juliartini, N. M., \& Arini, N. W. (2017). Penerapan Model Pembelajaran NHT untuk Meningkatkan Hasil Belajar IPA Siswa Kelas III. Journal of Education Action Research, 1(3), 240. https://doi.org/10.23887/jear.v1i3.12688.

Kurnia, V. T., \& Damayani, A. T. (2019). Keefektifan Model Pembelajaran Number Head Together (NHT) Berbantu Media Puzzle terhadap Hasil Belajar Matematika. Jurnal Ilmiah Sekolah Dasar, 3(2), 192-201. https://doi.org/10.23887/jisd.v3i2.17772.

Laksono, Y. S., Ariyanti, G., \& Santoso, F. G. I. (2016). Hubungan Minat Belajar Siswa terhadap Prestasi Belajar Matematika Siswa dalam Pembelajaran Kooperatif Tipe Stad Menggunakan Komik. Jurnal Edukasi Matematika Dan Sains, 1(2), 60-64. https://doi.org/10.25273/jems.v1i2.143.

Lestari, N. P. C. (2018). Penerapan Model Pembelajaran Kooperatif Tipe NHT Berbantuan Media Audio Visual untuk Meningkatkan Hasil Belajar IPA. Journal of Education Action Research, 2(4), 355. https://doi.org/10.23887/jear.v2i4.16331.

Mahfudi, H. N. (2020). Hubungan Peran Orang Tua terhadap Prestasi Belajar Siswa Kelas V SDN Legokulon 2. Education and Learning of Elementary School, 1(1), 1-9. http://ejournal.stkipmodernngawi.ac.id/index.php/ELES/article/view/177.

Maman, M., \& Rajab, A. A. (2016). The Implementation of Cooperative Learning Model 'Number Heads Together (NHT)' in Improving the Students' Ability in Reading Comprehension. International Journal of Evaluation and Research in Education (IJERE), 5(2), 174-180. https://doi.org/10.11591/ijere.v5i2.4536.

Persada, Y. I., Djatmika, E. T., \& Degeng, I. N. S. (2020). Pelaksanaan Pendekatan Scientific dalam Pembelajaran Tematik. Jurnal Pendidikan: Teori, Penelitian, Dan Pengembangan, 5(1), 114-120. https://doi.org/10.17977/jptpp.v5i1.13151.

Prayito. (2011). Pengembangan Perangkat Pembelajaran Matematika Humanistik Berbasis Konstruktivisme Berbantuan E-Learning Materi Segitiga Kelas VII. AKSIOMA Journal of Mathematics Education, 2(2). https://doi.org/10.26877/aks.v2i2/Septembe.37.

Rahmat, E. (2018). Penerapan Model Pembelajaran Problem Based Learning untuk Meningkatkan Prestasi Belajar IPS. Jurnal Ilmiah Sekolah Dasar, 1(3), 206. https://doi.org/10.23887/jisd.v1i3.11997.

Rufaidah, R. (2019). Peningkatan Kemampuan Komunikasi Matematis Melalui Model Pembelajaran Kooperatif Tipe Think Talk Write (Ttw) dengan Media LKPD pada Materi Relasi dan Fungsi Siswa Kelas VIII-B MTs Al-Ma'Arif Bocek Karangploso Tahun Pelajaran 2017/2018. JPM : Jurnal Pendidikan Matematika, 4(2), 95. https://doi.org/10.33474/jpm.v4i2.2621.

Simanungkalit, M. (2021). Penerapan Pembelajaran Aktif Kooperatif Melalui Metode Numbered Head Together (NHT) sebagai Upaya Meningkatkan Aktivitas dan Hasil Belajar IPA - Biologi. Jurnal $\begin{array}{lllll}\text { Teknologi Informasi \& Komunikasi Dalam Pendidikan, } & 7(1),\end{array}$ https://doi.org/10.24114/jtikp.v7i1.22635.

Sinaga, Amran Jahot \& Harun Sitompul, S. (2017). Pengaruh Strategi Pembelajaran dan Locus of Control terhadap Hasil Belajar Pendidikan Agama Siswa Kelas XI SMA Swasta St. Thomas 2 Medan. JURNAL TABULARASA PPS UNIMED, 14(2), 119-128. https://doi.org/10.24114/jt.v14i2.9648.

Suarni, D. A. K. (2017). Penerapan Model Pembelajaran Problem Based Learning untuk Meningkatkan Prestasi Belajar IPS. Jurnal Ilmiah Sekolah Dasar, 1(3), 206-214. https://doi.org/10.23887/jisd.v1i3.11997.

Susilo, Y., \& Khabibah, S. (2010). Peningkatan Motivasi Belajar Siswa Melalui Model Pembelajaran Kooperatif Tipe Numbered Head Together (NHT) Materi Ajar Perbandingan dan Fungsi Trigonometri pada Siswa Kelas X. MATHEdunesa, 2, 1.

SY, N., Corebima, A., \& Susilo, H. (2016). Pengaruh Strategi Pembelajaran Numbered Heads Together (NHT) terhadap Hasil Belajar Siswa SMA Negeri 1 Muara Badak. Jurnal Pendidikan: Teori, Penelitian, Dan Pengembangan, 1(10), 1993-1998-1998. https://doi.org/10.17977/jp.v1i10.7310.

Syafari, Y., \& Montessori, M. (2021). Analisis Pembelajaran Daring terhadap Motivasi Belajar dan Prestasi Belajar Siswa di Masa Pandemi Covid-19. Jurnal Basicedu, 5(3), 1294-1303. https://doi.org/10.31004/basicedu.v5i3.872.

Yenni, R. F. (2016). Penggunaan Metode Numbered Head Together (NHT) dalam Pembelajaran Matematika. Jurnal Penelitian Dan Pembelajaran Matematika, 9(2), 263-267. https://doi.org/10.30870/jppm.v9i2.1006. 